\title{
Tuning the morphologies of SiC nanowires via the change of the $\mathrm{Co}_{x} \mathrm{Si}_{y}$ melts
}

\author{
J. J. Chen ${ }^{1, *}$, Y. Pan ${ }^{2,3}$, W. H. Tang ${ }^{1}$ and Q. Shi ${ }^{3}$
}

$\mathrm{SiC}$ nanowires and $\mathrm{SiC} / \mathrm{SiO}_{2}$ core-shell structural nanowires were synthesized via a simple thermal evaporation of $\mathrm{Co}_{\mathrm{x}} \mathrm{Si}_{\mathrm{y}}$ melts at the temperature of $1500^{\circ} \mathrm{C}$. The morphologies and yields of those $\mathrm{SiC}$ nanowires can be tuned by altering the composition of $\mathrm{Co}_{\mathrm{x}} \mathrm{Si}_{\mathrm{y}}$. Nanowires obtained by thermal evaporation of $\mathrm{CoSi}$ are composed of $\mathrm{SiC} / \mathrm{SiO}_{2}$ core-shell nanostructures with lengths up to several hundreds of micrometers, diameters of $40 \sim 50 \mathrm{~nm}$, and the thickness of amorphous $\mathrm{SiO}_{2}$ wrapping shell about $20 \mathrm{~nm}$. SiC nanowires prepared by thermal evaporation of $\mathrm{CoSi}_{2}$ and $\mathrm{Co}_{2} \mathrm{Si}$ melt are found to be hexagonal-prism-shaped nanorods, and the diameter of those nanorods is about $150 \mathbf{~ n m}$ and the length is about 10 microns. All the $\mathrm{SiC}$ nanowires obtained possess [111] preferred growth direction with a high density stacking faults and twin defects. Taking into consideration the binary alloy diagram of $\mathrm{CoSi}$ and the participation of oxygen, we propose the vapor-solid growth mechanism of $\mathrm{SiC}$ nanowires and discuss the effect of the supersaturation of $\mathrm{SiO}$ on the morphology and yields of $\mathrm{SiC}$ nanowires.

Keywords: Silicon carbide; Nanowires; Morphology

Citation: J. J. Chen, Y. Pan, W. H. Tang and Q. Shi, "Tuning the morphologies of SiC nanowires via the change of the $\mathrm{Co}_{\mathrm{x}} \mathrm{Si}_{\mathrm{y}}$ melts”, Nano-Micro Lett. 2, 11-17 (2010). doi: 10.5101/nml.v2i1.p11-17

One-dimensional (1D) $\mathrm{SiC}$ nanomaterials, i.e., nanowires, nanorods, nanofibers, and nanocables have attracted much attention for many applications due to their excellent properties, such as high mechanical strength, high thermal stability, high thermal conductivity and wide band gap $[1,2]$. These unique properties make $\mathrm{SiC}$ a suitable candidate for various applications in nanoscale electronics [3,4], field-emission devices [5], optics [6], nanocomposites [7], photocatalysts [8,9], and hydrogen storage [10,11]. More recently, Niu et al. reported the excellent superhydrophobic property of $\mathrm{SiC}$ nanowires [12] and prepared superhydrophobic SiC nanowire coating [13]. An et al. also reported that $\mathrm{SiC}$ nanowires with special morphology are useful building blocks for nanoelectromechanical systems (NEMS) [14].

The promise of $1 \mathrm{D} \mathrm{SiC}$ nanomaterials has encouraged approaches to the synthesis of these materials. Up to now, a variety of approaches have been developed, for example, carbon nanotube confined reaction [15], arc discharge [16], laser ablation [17], sol-gel route [18], polymer pyrolysis route
[19], carbon thermal reduction [20], hydrothermal process [21], and chemical vapor deposition [22].

It is well known that some properties of nanomaterials can be modulated by varying their size and morphology [23]. Recently, some new techniques for preparing SiC nanowires with special morphology and microstructure have attracted researchers' attention. Zhang et al. reported on the synthesis of $\beta$-SiC nanowires with core-shell structures by rapidly heating a mixture of $\mathrm{SiO}$ and arc-discharge plasma pretreated carbon black [24]. Li et al. prepared centimeters-long SiC nanowires by pyrolysis of a polymer precursor with ferrocene as the catalyst [19]. Meng et al. synthesized $\mathrm{SiC} / \mathrm{SiO}_{2}$ chainlike nanostructures via a simple template/catalyst-free chemical vapor reaction approach with $\mathrm{Si}-\mathrm{SiO}_{2}$ mixture powder and $\mathrm{CH}_{4}$ as raw materials [25]. Guo et al. synthesized twinned $\mathrm{SiC}$ nanowires by the carbothermal reduction of a carbonaceous silica xerogel [26]. Up to now, 1D $\mathrm{SiC}$ nanomaterials with various morphologies have been synthesized, but control methods have rarely been discussed. Wang et al. reported a

1Department of Physics, Center for Optoelectronics Materials and Devices, Zhejiang Sci-Tech University, Hangzhou, 310018, China

2Department of Materials Science and Engineering, Zhejiang University, Hangzhou 310027, China

${ }^{3}$ Key Laboratory of Advanced Textile Materials and Manufacturing Technology (Zhejiang Sci-Tech University), Ministry of education, Hangzhou 310018, China

*Corresponding author. Email: chen@zstu.edu.cn. Telephone: +86-571-86843265 
technique to manipulate and control the morphology of vapor-liquid-solid (VLS) grown $\mathrm{SiC}$ nanowires by varying the pressure of the source species. They demonstrated that the diameter of the nanowires is strongly related to the pressure and pressure variation rate of the source species [14].

In previous study, we tuned the morphologies of $\mathrm{SiC}$ nanowires by simply altering the reaction temperature [27]. In this letter, we turn to the preparation of $\mathrm{SiC}$ nanowires with varied morphologies by altering the supersaturation of $\mathrm{SiO}$ via changing the composition of metal silicide. In this work, $\mathrm{Co}_{2} \mathrm{Si}$, $\mathrm{CoSi}$ and $\mathrm{CoSi}_{2}$ alloy powder were used as the starting materials respectively. After heating alloy powder in a graphite crucible in argon atmosphere for $5 \mathrm{~h}$, a greenish layer was found attached on the surface of the graphite substrate. Characterizations of the products showed that they are all single crystalline 3C-SiC nanowires, but the morphologies and yields of the nanowires are different. Taking into account the possible reactions between intermediate gas phases and the CoSi binary alloy phase diagrams, we think the degree of supersaturation of $\mathrm{SiO}$ is the key factor deciding the growth morphologies and yields of SiC nanowires. This metal silicide solution technique provides an effective method for the control of supersaturation of $\mathrm{SiO}$, and it is valuable to realize the controlled growth of $\mathrm{SiC}$ nanostructures.

The cobalt silicide alloy $\left(\mathrm{Co}_{2} \mathrm{Si}, \mathrm{CoSi}\right.$ and $\left.\mathrm{CoSi}_{2}\right)$ was prepared by melting commercially available Co (99.97\%) and $\mathrm{Si}(99.9999 \%)$ four times in a vacuum furnace to achieve chemical homogeneity. 20 gram alloys $\left(\mathrm{Co}_{2} \mathrm{Si}, \mathrm{CoSi}\right.$ and $\left.\mathrm{CoSi}_{2}\right)$ were broken and ground into powder and put in three graphite crucibles respectively. The crucibles were then covered by a polished graphite plate. Three graphite crucibles containing the cobalt silicide alloy were then moved to the Astro furnace and the base pressure in the furnace chamber was pumped up to 1 $\mathrm{Pa}$ through a rotary pump. Argon gas was then introduced until the furnace pressure reached $400 \mathrm{~Pa}$. The furnace was heated at a rate of $30^{\circ} \mathrm{C} / \mathrm{min}$ to $1500^{\circ} \mathrm{C}$ and maintained at the temperature for 5 hours, and then the furnace was naturally cooled to room temperature. The schematic drawing of the furnace and the setup is shown in Fig. 1. Figure 2 shows the macroscopical photographs of the nanowires growing on the surface of the graphite plates. Figure 2(a) shows a thin and greenish colored layer on the surface of the graphite plate over CoSi melt and the yield of the product is very low. The surface of the graphite

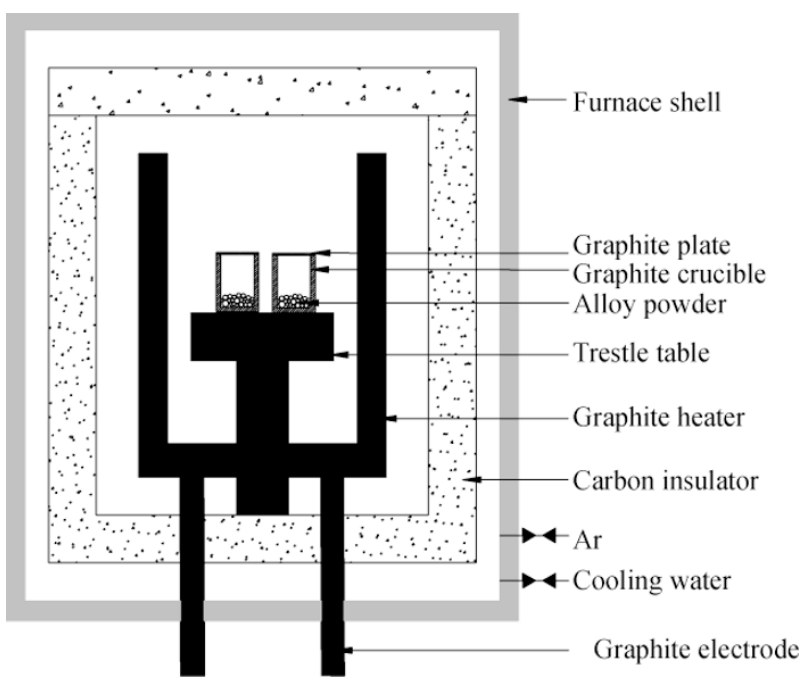

FIG. 1. Schematic drawing of the furnace and the setup.

plate over the $\mathrm{Co}_{2} \mathrm{Si}$ melt was found to be covered with a thick and greenish colored layer, as Fig. 2(b) shows. The product synthesized by $\mathrm{CoSi}_{2}$ melt is showed in Fig. 2(c).

The products collected from the surface of the graphite plate were investigated by X-ray diffraction (XRD, Rigaku, $\mathrm{D} / \mathrm{max}-\gamma \mathrm{A}$ and $\mathrm{Cu}-\mathrm{K} \alpha$ radiation), field-emission scanning electron microscopy (FE-SEM, FEI-SIRION100, operated at 5 $\mathrm{KV}$ ). Further structural and compositional analysis of individual nanowire was performed using transmission electron microscopy (TEM, JEOL-1200EX) and high-resolution transmission electron microscopy (HRTEM, JEOL-2010).

Figure 3(a), (b), and (c) show the XRD patterns of three products, respectively. From Fig. 3, three major diffraction peaks at $36^{\circ}, 60^{\circ}$ and $72^{\circ}$ were observed, which can be indexed as the $\{111\},\{220\}$ and $\{311\}$ reflections of cubic SiC (3C-SiC, the lattice constant $\alpha=0.4370 \mathrm{~nm}$ ). These values are almost identical to the known values for standard $\beta$-SiC (JCPDS Card No. 29-1129). The sharp diffraction peaks indicate that the products are highly crystalline. The low-intensity peak at $2 \theta=$ $33.5^{\circ}$ (marked with 'SF') is usually ascribed to the stacking faults in the (111) planes. It is thus established that the as-grown products mainly consist of $3 \mathrm{C}-\mathrm{SiC}$.

FESEM and TEM were employed to investigate the morphology and microstructure of the as-grown products.

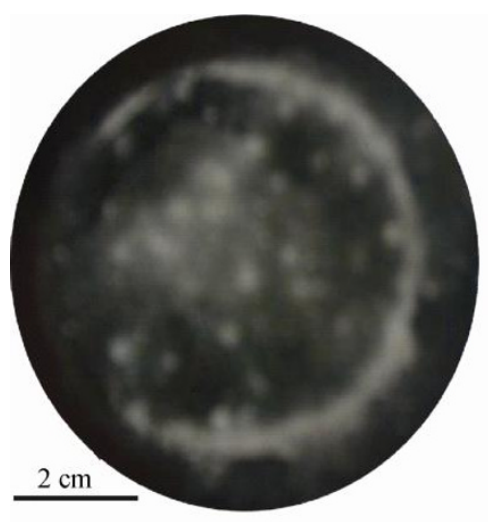

(a)

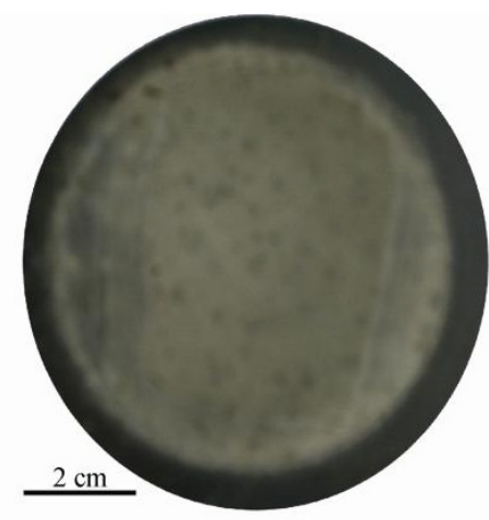

(b)

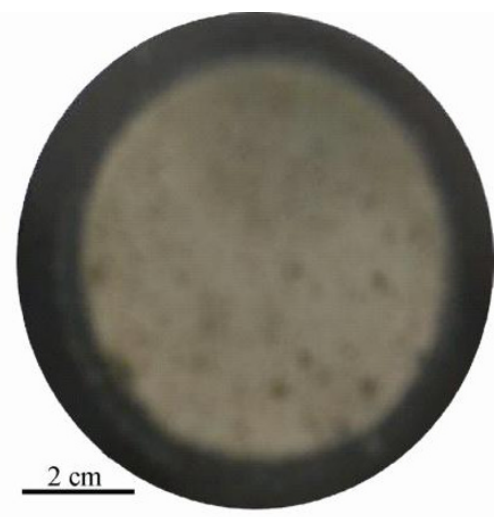

(c)

FIG. 2. Macroscopical photographs of the products on the graphite plates. (a) The graphite plate over the CoSi melt. (b) The graphite plate over the Co $\mathrm{S}_{2} \mathrm{Si}$ melt. (c) The graphite plate over the $\mathrm{CoSi}_{2}$ melt. 
Figure 4(a) is a typical FESEM image of the product synthesized by thermal evaporation of the CoSi melt. In Fig. 4(a) and (b), it can be seen that the nanowires have almost uniform diameters and smooth surface. The diameters of nanowires can be roughly estimated in the range of $60 \sim 90 \mathrm{~nm}$ and the lengths are several hundred microns.

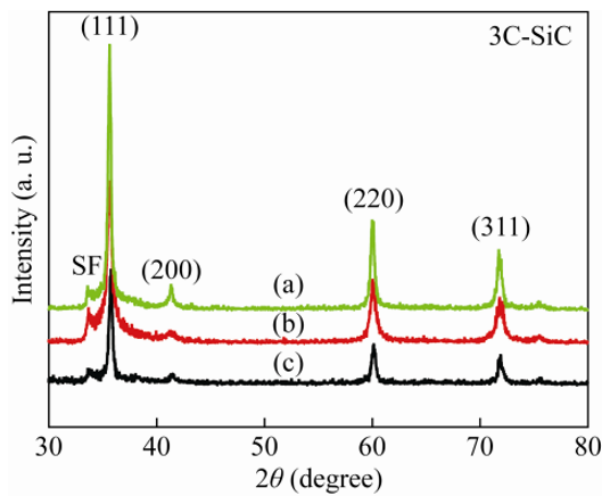

FIG. 3. XRD patterns of the products obtained by different $\mathrm{Co}_{\mathrm{x}} \mathrm{Si}_{\mathrm{y}}$ melt: (a) CoSi melt, (b) $\mathrm{Co}_{2} \mathrm{Si}$ melt, (c) $\mathrm{CoSi}_{2}$ melt, respectively.

The TEM images in Fig. 4(c) and (d) show detailed structure of the nanowires. The core-shell nanocabled structure of $\mathrm{SiC} / \mathrm{SiO}_{2}$ nanowires was observed. The streaks of the selected electron diffraction (SAED) spots along [112] (inset of Fig. 4(c)) imply the presence of stacking faults normal to [111], the growth direction. Two weak amorphous phase diffraction haloes in the SAED can be ascribed to amorphous $\mathrm{SiO}_{2}$ shell. It is also worth noting that in Fig. 4(d) the surface of the core is partly smooth (marked with A) and partly rough (marked with B). The smooth part shows no defects, while the rough part is full of planar defects, i.e. stacking faults perpendicular to the rod axis. The unique microstructure caused by stacking faults has been reported in our previous work [27].

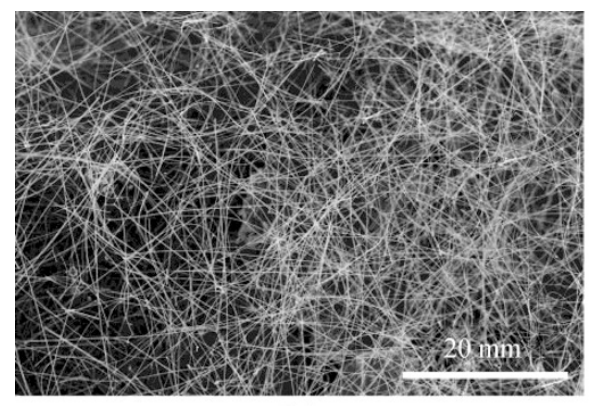

(a)

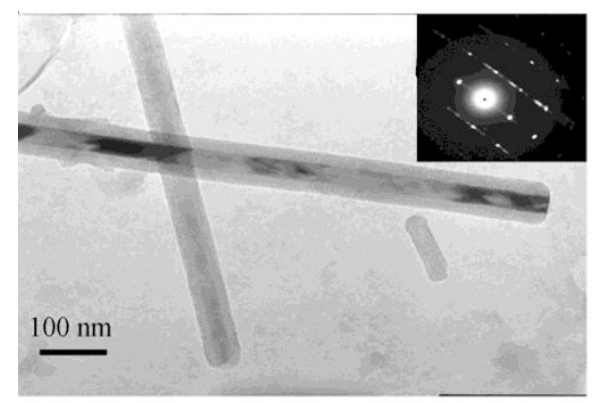

(c)
Figure 5(a) and (b) show a high yield of the nanowires prepared by thermal evaporation of the $\mathrm{CoSi}_{2}$ melt. The $\mathrm{SiC}$ nanowires are rod-like, the diameter is about $150 \mathrm{~nm}$ and the length is up to tens of microns. Magnified FESEM image, Fig. 5(b), further shows that the SiC nanowires are hexagonal prism shaped, and the surface of the nanoprism looks slightly zigzagged. Figure 5(c) and (d) are TEM images of individual SiC nanoprism with different magnifications. The dark contours perpendicular to the axis of the nanoprism imply the presence of stacking faults normal to the growth direction. The HRTEM image (see Fig. 5(d)) of the nanoprism further confirms the existence of stacking faults on the (111) planes. Some microtwins and regularly arrayed fringes are also shown in Fig. $5(\mathrm{~d})$. The spacing between the fringes is $0.25 \mathrm{~nm}$, the $d$ spacing of the (111) plane of $3 \mathrm{C}$-SiC. It is worth noting that a layer of $\mathrm{SiO}_{2}$ nanofilm can also be observed in Fig. 5(d).

The nanowires which were synthesized by thermal evaporation of the $\mathrm{Co}_{2} \mathrm{Si}$ melt are displayed in Fig. 6(a) and (b). It shows that the product is $\mathrm{SiC}$ nanowires with their lengths up to tens of micrometers. Magnified FESEM image (see Fig. 6(b)) further shows that the $\mathrm{SiC}$ nanowires are hexagonal prism shaped, and the diameters are about $100 \mathrm{~nm}$. The surface of the hexagonal prisms is very smooth and clean. TEM image and the SAED pattern of a SiC nanowire are shown in Fig. 6(c). A high density of stacking faults is again observed. The streaks of the SAED spots along [112] (inset of Fig. 6(c)) imply the presence of stacking faults normal to [111]. The HRTEM image (see Fig. 6(d)) of the nanoprism also confirms the high density of stacking faults. The $\mathrm{SiC}$ nanowires are also wrapped by thin amorphous $\mathrm{SiO}_{2}$ layers.

The results presented above showed that the size, morphology and yield of $\mathrm{SiC}$ nanowires can be tuned by changing the composition of the cobalt silicide alloy. In the present experiment, no metal droplet was found on the ends of the nanowires. Thus, the vapor-solid (VS) growth mechanism is

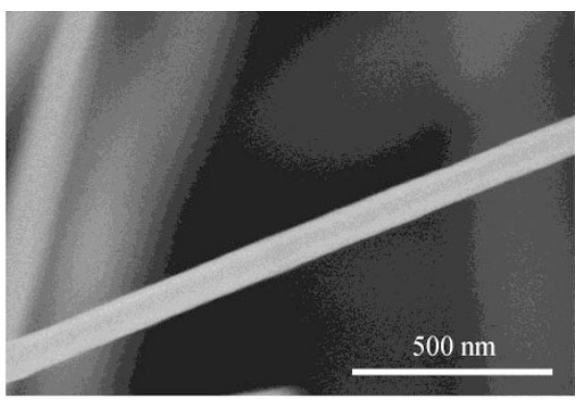

(b)

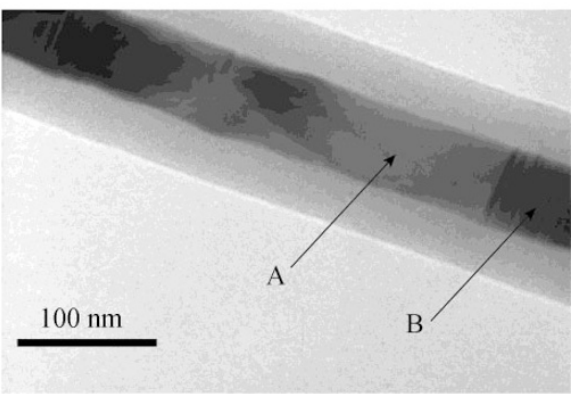

(d)

FIG. 4. SiC nanowires obtained by CoSi melt. (a) and (b) representative FESEM images of the SiC nanowires. (c) The TEM image of SiC nanwires with a core-shell $\mathrm{SiC} / \mathrm{SiO}_{2}$ structure and corresponding SAED pattern (inset). (d) Magnified TEM image of a core-shell $\mathrm{SiC} / \mathrm{SiO}_{2}$ nanowire with smooth (A) and rough (B) surfaces. 


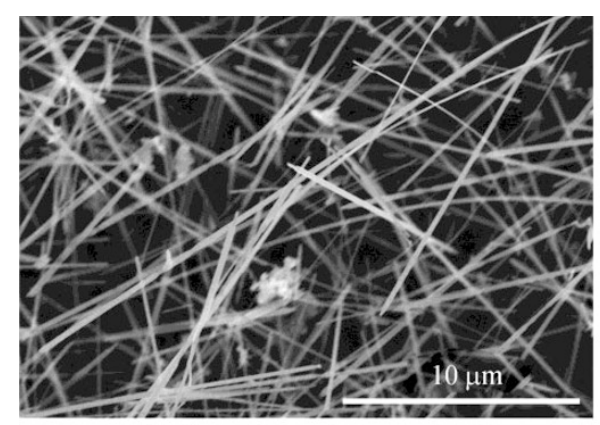

(a)

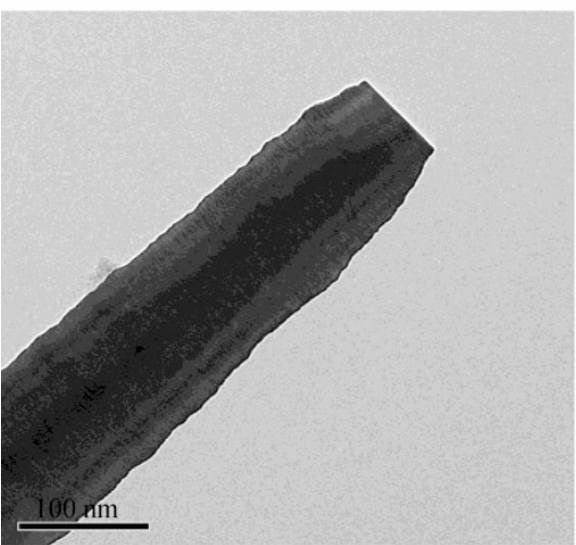

(c)

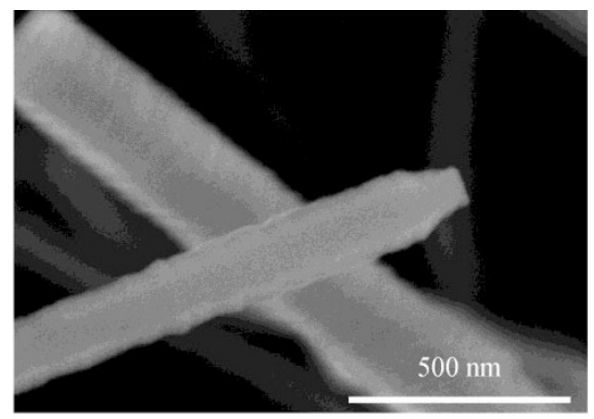

(b)

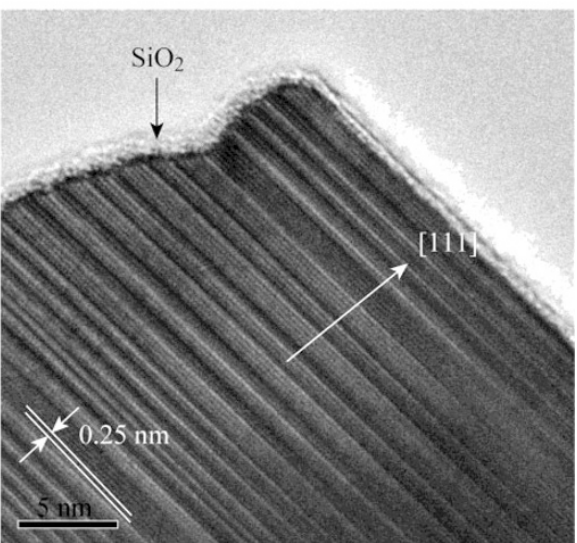

(d)

FIG. 5. SiC nanowires obtained by $\mathrm{CoSi}_{2}$ melt. (a) and (b) Representative FESEM images of the SiC nanoprisms. (c) Typical TEM image of an individual SiC nanoprism. (d) HRTEM image of a single crystalline nanoprism.

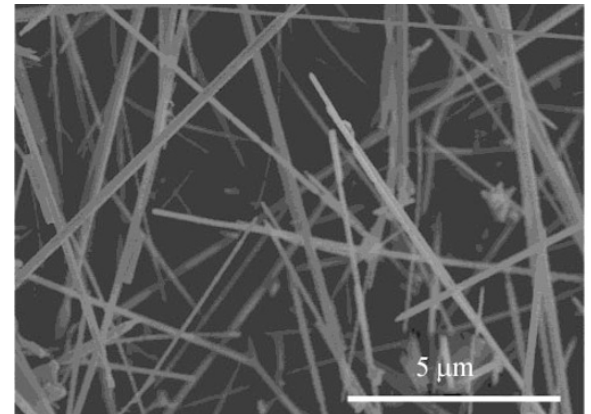

(a)

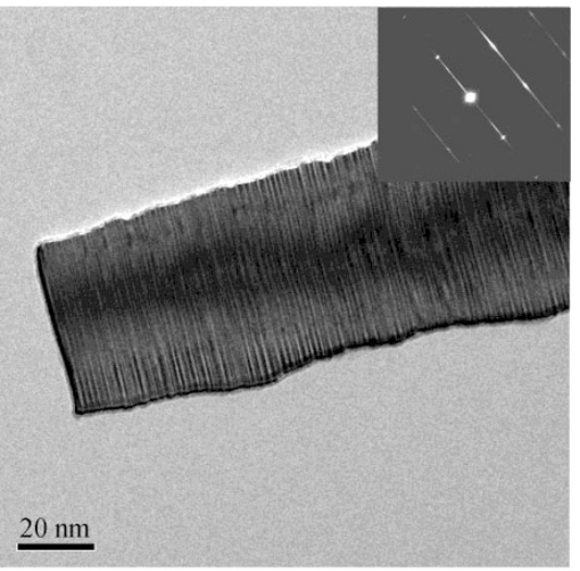

(c)

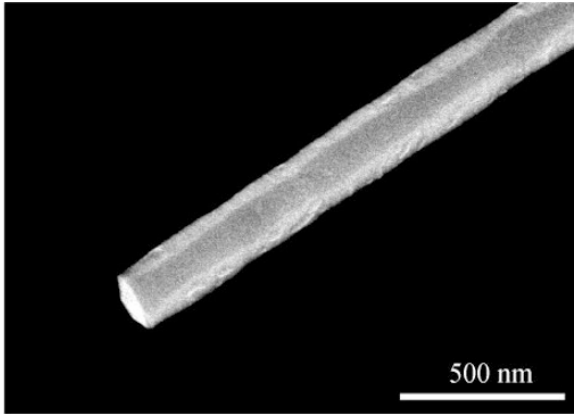

(b)

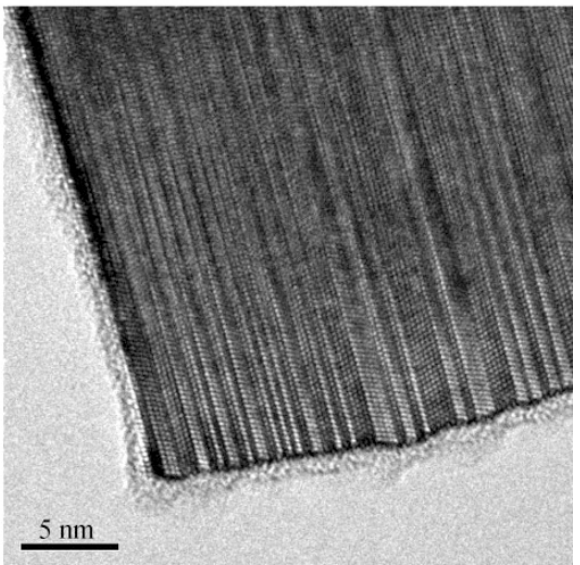

(d)

FIG. 6. SiC nanowires obtained by $\mathrm{Co}_{2} \mathrm{Si}$ melt. (a) and (b) representative FESEM images of the SiC nanoprisms. (c) Typical TEM image of an individual SiC nanoprism and corresponding SAED pattern (inset). (d) HRTEM image of a single crystalline nanoprism. 
more plausible than the vapor-liquid-solid (VLS) one. The vapor-solid mechanism proposed by $\mathrm{Wu}$ et al. [27] can be used to understand the growth process of $\mathrm{SiC}$ nanowires. In the experiment, as the temperature rises to $1,500^{\circ} \mathrm{C}, \mathrm{Co}_{\mathrm{x}} \mathrm{Si}_{\mathrm{y}}$ powder will vaporize and react with the residual oxygen from the impurity of argon gas to produce $\mathrm{SiO}$. $\mathrm{SiC}$ can be generated by the following reactions:

$$
\begin{aligned}
& \mathrm{SiO}(\mathrm{g})+\mathrm{C}(\mathrm{s})=\mathrm{SiC}(\mathrm{s})+\mathrm{CO}(\mathrm{g}) \\
& \mathrm{SiO}(\mathrm{g})+3 \mathrm{CO}(\mathrm{g})=\mathrm{SiC}(\mathrm{s})+2 \mathrm{CO}_{2}(\mathrm{~g}) \\
& 3 \mathrm{SiO}(\mathrm{g})+\mathrm{CO}(\mathrm{g})=\mathrm{SiC}(\mathrm{s})+2 \mathrm{SiO}_{2}(\mathrm{~s})
\end{aligned}
$$

To understand the growth process of the nanowires, a mechanism illustrated in Fig. 7 is proposed. Basically, the formation of these nanowires can be divided into two stages, i.e. nucleation and growth.

In the nucleation stage, the carbon atoms on the surface of graphite plate could react with $\mathrm{SiO} / \mathrm{Si}$ vapor to form $\mathrm{SiC}$ embryos by heterogeneous nucleation (reaction (1), Fig. 7(a)). A just-formed $\mathrm{SiC}$ nucleus should be a two-dimensional (2D) disc on the graphite surface with Si layer on the top and $\mathrm{C}$ layer on the bottom (see Fig. 7(b)), which will be the first (111) plane of a subsequent $\mathrm{SiC}$ nanowire. The top $\mathrm{Si}$ layer of $\mathrm{SiC}$ embryos may still have Si-O bonds, which could absorb $\mathrm{CO}$ molecules, and react with each other (reaction (2)) to generate a $\mathrm{C}$ layer covering the Si layer, as Fig. 7c showed.

In the subsequent growth stage, the newly formed $\mathrm{C}$ layer would absorb $\mathrm{SiO}$ to form the second $\mathrm{Si}$ layer, i.e. the second (111) plane of 3C-SiC, and a layer-by-layer growth along [111] direction is realized. The small amorphous $\mathrm{SiO}_{2}$ layers about $0.5 \mathrm{~nm}$ in thickness showed in Fig. 5(d) and Fig. 6(d) may be the evidence of the layer-by-layer growth mechanism. The $2 \mathrm{D}$ $\mathrm{SiC}$ nucleus would also grow vertically along the [111] direction to form a nanowire. Since it requires long distance diffusion of carbon atoms along the growing nanowires, reaction (1) is not considered to be mainly responsible for the $\mathrm{SiC}$ nanowire growth. Instead, in reaction (2), SiC generated by the reaction of $\mathrm{SiO}$ and $\mathrm{CO}$ vapor deposit on the tip of the growing $\mathrm{SiC}$ nanowire. The preferential growth as well as continuous generation and reaction of $\mathrm{SiO}$ and $\mathrm{CO}$ at the tips of the nanowires account for the main reason why the $\mathrm{SiC}$ nanowire can grow so long with a large aspect ratio. The oxide-assisted cluster-solid mechanism proposed by Zhang et al. [28], which was established to interpret the growth process of $\mathrm{Si} / \mathrm{SiO}_{2}$ nanowires, may be used to understand the growth process of $\mathrm{SiC}$ nanowires.
During the cooling stage, with temperature decreasing, reaction (3) would occur and lead to a decrease in enthalpy and Gibbs energy [29-31], which is thermodynamically favorable at low temperature. The sufficient $\mathrm{SiO}$ vapor would preferentially nucleate and grow around the nanowires by a vapor-solid mechanism, and $\mathrm{SiO}_{2}$ was formed on the surface of the $\mathrm{SiC}$ nanowires by the reaction (3) during the cooling stage. This two-stage vapor-solid growth mechanism of $\mathrm{SiC} / \mathrm{SiO}_{2}$ core-shell nanocables has been reported by some researchers $[25,32]$.

Now it is generally accepted that the control of supersaturation is a prime consideration in obtaining 1D nanostructure, because there is strong evidence that the degree of supersaturation determines the prevailing growth morphology [33]. In the experiment, the size, morphology and yield of $\mathrm{SiC}$ nanowires can also be controlled by the supersaturation of $\mathrm{SiO}$ generated from the reaction of $\mathrm{Co}_{\mathrm{x}} \mathrm{Si}_{\mathrm{y}}$ and oxygen, and $\mathrm{CO}$ generated from the reaction of graphite and oxygen. The supersaturation of $\mathrm{SiO}$ is determined by the $\mathrm{SiO}$ gas partial pressure which can be tuned by changing the alloy composition of $\mathrm{Co}_{\mathrm{x}} \mathrm{Si}_{\mathrm{y}}$. The CoSi binary alloy phase diagrams show the melting point of $\mathrm{CoSi}, \mathrm{Co}_{2} \mathrm{Si}$ and $\mathrm{CoSi}_{2}$ are $1460^{\circ} \mathrm{C}, 1334^{\circ} \mathrm{C}$ and $1326^{\circ} \mathrm{C}$ respectively [34]. At the experiment temperature $\left(1500^{\circ} \mathrm{C}\right)$, the partial pressure of $\mathrm{SiO}$ in the crucibles containing $\mathrm{Co}_{2} \mathrm{Si}$ and $\mathrm{CoSi}_{2}$ alloy can be much higher than that in crucible containing CoSi alloy. At the high $\mathrm{SiO}$ partial pressure, a great quantity of $\mathrm{SiC}$ nucleus are formed due to the high $\mathrm{SiO}$ supersaturation, therefore, the high yields of $\mathrm{SiC}$ nanowires can be realized, while at the low $\mathrm{SiO}$ partial pressure, the nucleus can hardly be formed. In this experiment, a small quantity of $\mathrm{SiC}$ nucleus was formed, and the size of nucleus was small. Since the initial nuclear size determines the diameter of the nanowires, the diameter of $\mathrm{SiC}$ nanowires synthesized by $\mathrm{CoSi}$ melt is smaller than that of $\mathrm{SiC}$ nanowires synthesized by $\mathrm{Co}_{2} \mathrm{Si}$ and $\mathrm{CoSi}_{2}$ melt. Meanwhile, due to the low yields, there were not many $\mathrm{SiC}$ nanowires' tips for new generated embryos (by reaction (2)) to deposit. As a result, the length of the nanowires synthesized by $\mathrm{CoSi}$ melt is much longer than that of the nanowires synthesized by $\mathrm{Co}_{2} \mathrm{Si}$ and $\mathrm{CoSi}_{2}$ melt. The thick $\mathrm{SiO}_{2}$ shell of $\mathrm{SiC} / \mathrm{SiO}_{2}$ nanocables was also formed by the reaction (3) for low $\mathrm{SiC}$ nanowire yields.

In summary, we report a new metal silicide thermal evaporation technique to control the morphologies and yields of $\mathrm{SiC}$ nanowires by varying the composition of the alloys. Nanowires with different morphologies were obtained by simple thermal evaporation of $\mathrm{Co}_{\mathrm{x}} \mathrm{Si}_{\mathrm{y}}$ melts at $1500^{\circ} \mathrm{C}$. The ultra-long $\mathrm{SiC} / \mathrm{SiO}_{2}$ nanocables obtained by thermal evaporation of $\mathrm{CoSi}$

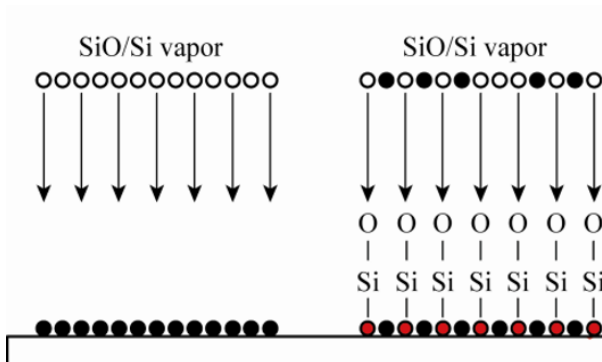

(a)

(b)

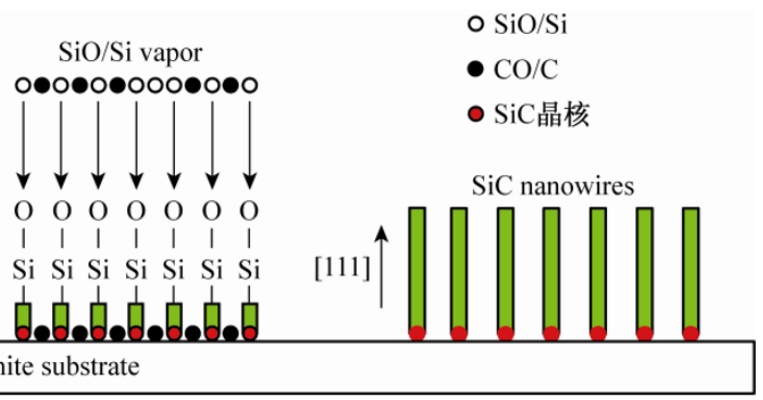

(c)

(d)

FIG. 7. Schema showing the proposed formation process of $\mathrm{SiC}$ nanowires: (a) $\mathrm{SiO} / \mathrm{Si}$ vapor reaction of carbon atoms. (b) Formation of $\mathrm{SiC}$ embryos with $\mathrm{Si}$ layer on the top and $\mathrm{C}$ layer on the bottom. (c) Formation of $3 \mathrm{C}-\mathrm{SiC}$ embryos with $\mathrm{C}$ layer on the top and (d) formation of $\beta$-SiC nanowires and the growth direction along [111]. 
melt have a small diameter (about $60 \mathrm{~nm}$ ), but the yield is very low. $\mathrm{SiC}$ nanowires prepared by thermal evaporation of the $\mathrm{CoSi}_{2}$ and $\mathrm{Co}_{2} \mathrm{Si}$ melt are rod-like, the diameter is about $150 \mathrm{~nm}$ and the length is up to tens of microns. The vapor-solid growth mechanism and the effect of supersaturation of $\mathrm{SiO}$ on nanowire morphology and yields were discussed. The supersaturation of $\mathrm{SiO}$ can also be controlled by using other metal silicides, for example, $\mathrm{Fe}_{\mathrm{x}} \mathrm{Si}_{\mathrm{y}}$ alloy.

This work is supported by the National Nature Science Foundation of the People's Republic of China (Grant no. 50902124) and the National Basic Research Program of China (973 Program) (Grant no. 2010CB933501). The authors also gratefully acknowledge the financial support from the Zhejiang Provincial Natural Science Foundation (Grant no. Y4090468) and Science and Technology Department of Zhejiang Province (Grant no. 2009F70046).

Received 19 January 2010; accepted 28 January 2010; published online 28 February 2010.

\section{References}

1. E. W. Wong, P. E. Sheehan and C. M. Lieber, Science 277, 1971 (1997). doi:10.1126/science.277.5334.1971

2. C. C. Tang, Y. Bando, T. Sato and K. Kurashima, Appl. Phys. Lett. 80, 4641 (2002). doi:10.1063/1.1487926

3. K. Rogdakis, M. Bescond, E. Bano and K. Zekentes, Nanotechnology 18, 475715 (2007). doi:10.1088/0957$\underline{4484 / 18 / 47 / 475715}$

4. W. Zhou, X. Liu and Y. Zhang, Appl. Phys. Lett. 89, 223124 (2006). doi:10.1063/1.2398902

5. D. W. Kim, Y. J. Choi, K. J. Choi, J. G. Park, J. H. Park, S. M. Pimenov, V. D. Frolov, N. P. Abanshin, B. I. Gorfinkel, N. M. Rossukanyi and A. I. Rukovishnikov, Nanotechnology 19, 225706 (2008). doi:10.1088/0957$\underline{4484 / 19 / 22 / 225706}$

6. J. J. Niu and J. N.Wang, J. Phys. Chem. B 111, 4368 (2007). doi:10.1021/jp070682d

7. W. Yang, H. Araki, C. C. Tang, S. Thaveethavorn, A. Kohyama, H. Suzuki and T. Noda, Adv. Mater. 17, 1519 (2005). doi:10.1002/adma.200500104

8. J. M. Nhut, R. Vieira, L. Pesant, J. P. Tessonnier, N. Keller, G. Ehret, C. Pham-Huu and M. Ledoux, J. Catal. Today 76, 11 (2002). doi:10.1016/S0920-5861(02)00 $\underline{206-7}$

9. W. Zhou, L. Yan, Y. Wang and Y. Zhang, Appl. Phys. Lett. 89, 013105 (2006). doi:10.1063/1.2219139

10. G. Mpourmpakis, G. E. Froudakis, G. P.Lithoxoos and J. Samios, Nano Lett. 6, 1581 (2006). doi:10.1021/n106 $\underline{03911}$

11. V. G. Pol, S. V. Pol, A. Gedanken, S. H. Lim, Z. Zhong and J. Lin, J. Phys. Chem. B 110, 11237 (2006). doi:10.1021/jp061407e

12. J. J. Niu, J. N. Wang and Q. F. Xu, Langmuir 24, 6918 (2008). doi:10.1021/la800494h

13. J. J. Niu and J. N. Wang, J. Phys. Chem. B 113, 2909 (2009). doi:10.1021/jp808322e

14. H. Wang, Z. Xie, W. Yang, J. Fang and L. An, Cryst. Growth Des. 8, 3893 (2008). doi:10.1021/cg8002756

15. H. Dai, E. W. Wang, Y. Z. Liu, S. S. Fan and C. M. Lieber, Nature 357, 769 (1995). doi:10.1038/375769a0

16. T. Seeger, P. Kohler-Redlich and M. Ruhle, Adv. Mater. 12, 279 (2000). doi:10.1002/(SICI)1521-4095(200002) 12:4<279::AID-ADMA279>3.0.CO;2-1

17. W. S. Shi, Y. F. Zheng, H. Y. Peng, N. Wang, C. S. Lee and S. T. Lee, J. Am. Ceram. Soc. 83, 3228 (2000). doi:10.1111/j.1151-2916.2000.tb01714.X

18. X. K. Li, L. Liu, Y. X. Zhang, S. D. Shen, S. Ge and L. C. Ling, Carbon 39, 159 (2001). doi:10.1016/S0008-6223 (00)00020-8

19. G. Li, X. D. Li, Z. D. Chen, J. Wang, H. Wang and R. C Che, J. Phys. Chem. C 113, 17655 (2009). doi:10.1021/ ip904277f

20. G. Z. Shen, Y. Bando, C. H. Ye, B. D. Liu and D. Golberg, Nanotechnology 17, 3468 (2006). doi:10.1088/0957-4484/ $\underline{17 / 14 / 019}$

21. G. C. Xi, Y. K. Liu, X. Y. Liu, X. Q. Wang and Y. T. Qian, J. Phys. Chem. B 110, 14172 (2006). doi:10.1021/ ip0617468

22. R. B. Wu, Y. Pan, G. Y. Yang, M. X. Gao, J. J. Chen, L. L. Wu, R. Zhai and J. Lin, Phys. Chem. C 111, 6233 (2007).

23. C. Burda, X. B. Chen, R. Nararyanan and M. A. EI-Sayed, Chem. Rev. 105, 1025 (2005). doi:10.1021/cr030063a

24. F. L. Wang, L. Y. Zhang and Y. F. Zhang, Nanoscale Res Lett. 4, 153 (2009). doi:10.1007/s11671-008-9216-3

25. Z. Li, W. Gao, A. Meng, Z. Geng and L. Gao, J. Phys. Chem. C 113, 91 (2009). doi:10.1021/jp806346d

26. D. H. Wang, D. Xu, Q. Wang, Y. J. Hao,G. Q. Jin, X. Y. Guo and K. N. Tu, Nanotechnology 19, 215602 (2008). doi:10.1088/0957-4484/19/21/215602

27. R.Wu, B. Li, M. Gao, J. Chen,Q. Zhu and Y. Pan, Nanotechnology 19, 335602 (2008). doi:10.1088/0957$\underline{4484 / 19 / 33 / 335602}$

28. Y. F. Zhang, Y. H. Tang, N. Wang, C. S. Lee, I. Bello and S. T. Lee, J. Cryst. Growth 197, 136 (1999). doi:10.1016 
/S0022-0248(98)00953-1

29. C. Vix-Guterl and P. Ehrburger, Carbon 35, 1587 (1997). doi:10.1016/S0008-6223(97)00117-6

30. G. Y. Yang, R. B.Wu, J. J. Chen, Y. Pan, R. Zhai, L. L.Wu and J. Lin, Nanotechnology 18, 155601 (2007). doi:10.1088/0957-4484/18/15/155601

31. C. H. Liang, G. W. Meng, L. D. Zhang, Y. C. Wu and Z. Cui, Chem. Phys. Lett. 329, 323 (2000). doi:10.1016/ S0009-2614(00)01023-X
32. B. Li, R. Wu, Y. Pan, L. Wu, G. Yang, J. Chen and Q. Zhu, J. Alloy. Comp. 462, 446 (2008). doi:10.1016/ j.jallcom.2007.08.076

33. Y. N. Xia, P. D. Yang, Y. G. Sun, Y. Y. Wu, B. Mayers, B. Gates, Y. D. Yin, F. Kim and Y. Q. Yan, Adv. Mater. 15, 353 (2003). doi:10.1002/adma.200390087

34. K. Ishida, T. Nishlzawa and M. E. Schlesinger, J. Phase Equilib. 12, 578 (1991). doi:10.1007/BF02645074 